\title{
Friction Stir Welding Aluminum Alloy H20-H20 Conventional and Overlap Joints Mechanical Properties
}

\author{
Omid Ali Zargar \\ Department of mechanical engineering - Jawaharlal Nehru technological university Hyderabad Kukatpally , Hyderabad-500085, \\ Andra Pradesh India \\ *Corresponding Author:omid.alizargar@gmail.com
}

Copyright (C) 2014 Horizon Research Publishing All rights reserved.

\begin{abstract}
In this paper the effect of conventional and overlap joints with different depth in tensile properties of friction stir welded joint of aluminum alloys H20-H20 discussed in details. There were number of investigation in mechanical properties of conventional joints. In this paper overlap joint mechanical properties compared with conventional joints. The results found much useful information for any future design activities due to the wide application of aluminum alloy $\mathrm{H} 20$ in this area specially in choosing joint types in friction stir welding. Furthermore hardness mechanical properties of welded joint aluminum alloy $\mathrm{H} 20-\mathrm{H} 20$ discussed in details.
\end{abstract}

Keywords Aluminum Alloy H20, Friction Stir Welding (FSW), Tensile Test, Vickers Hardness Test

\section{Introduction}

Friction Stir Welding (FSW) is a new developed method that mechanical stirring between two parts of work piece and tool cause welding. In this method materials that previously was not weldable could weld by $\mathrm{CNC}$ milling machines. FSW is a perfect method for manufacturing the complex shape hollow products. Orbital FSW also has a wide application in steel pipe maintenance in oil industries by using robotics type $\mathrm{CNC}$ machines.

Friction Stir Welding (FSW) is a new welding method that could applied for wide range of metals and alloys compared to conventional welding methods. FSW could apply for same or different types of materials like brass, mix copper and titanium as well as aluminum. In addition, wide different type of machine in different type of application and material areas could be used in FSW like longitudinal, horizontal and vertical in manufacturing area like the floor panel of modern train or ships. Furthermore, FSW has wide applications in modern automotive industries.

The principal of FSW base on penetrating a tool in to the joint surface after adjusting process in $\mathrm{CNC}$ milling machine (feed of the process) due to the type of materials and tool shapes. Besides, rotational speed and travel speed are the second and third main process characteristics. the process parameter could adjusted properly after tool, machine and material documents consideration .In complex applications the $\mathrm{CNC}$ machine need to programed by CAM methods accurately, while in simple applications an ordinary CNC milling machine programing could applied in a linear path. Same CNC program could apply for work piece backside in reverse direction [1]. Schematic diagram of FSW shown in figure 1 .

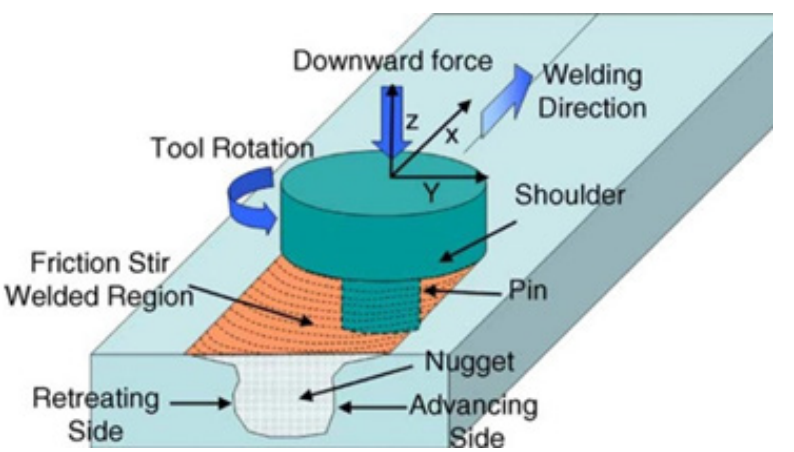

\section{Literature Review and Significant of This Study}

Three main type of research take placed in previous investigations on friction stir welding first mathematical and computer base modeling of the process. There are too many investigation area in FSW modeling and the number of areas increasing every day some of the previous investigations are, Prediction of Friction Stir Welding Characteristic Using Neural Network, Numerical Simulation of the Friction Stir Welding Process ,Heat Transfer Analysis during Friction Stir Welding, 3D numerical simulation of the three stages of Friction Stir Welding based on friction parameters calibration, 3D numerical simulation of the three stages of Friction Stir Welding based on friction parameters calibration, Numerical Simulation of Transient Temperature in Friction Stir Welding, Finite element modeling and failure prediction of friction stir welded blanks and 
Optimizing the Process Parameters of FSW. The significant of this paper is to discuss mechanical properties of overlap and conventional joints for aluminum alloys for the first time. One of the common joint in mechanical engineering design is overlap joints the nature of the challenges in design process is how can we decide the type of joint in primary design for different application. Previous work in this field all compare welded joint with different tools and different materials work piece in this project we want to compare the mechanical properties of conventional and overlap joints. The results will help design process in different situation. It is worthy to know that Excessive welding heat input of any high load may cause the peak load and energy absorption capability significantly reduce. Maladjustment of the process parameter may cause change in pullout failure location from base metal to weld nugget edge due to severe indentation[3].corrosion Resistance of aluminum alloy H20 is very good. Besides, its strength is quite satisfactory. Aluminum alloy $\mathrm{H} 20$ widely used by different industries like structural and platform manufacturing. Aluminum alloy H20 machinability is excellent with a good control in grain structure these characteristics make aluminum alloy H20 excellent for FSW process Aluminum alloy H20 a medium Strength alloy with excellent corrosion Resistance. Alloy $\mathrm{H} 20$ is known as a structural alloy. In plate form, H20 is the alloy most commonly used for machining. As a relatively new alloy, the higher strength of $\mathrm{H} 20$ has seen it replace 6061 in many applications. The addition of a large amount of manganese controls the Grain structure which in turn results in a stronger alloy. It is difficult to produce thin walled, complicated extrusion shapes. The extruded surface finish is not as smooth as other similar strength alloys. In the T4 and T6 temper, alloy H20 machines well and produce tight coils of swarf when chip breakers are used [4].

\section{Materials and Methods}

The CNC MILLING MACHINE BMV 45 used for this project in a work shop in Balanagar Hyderabad India. CNC milling machine specification represented in table 1 .

Table 1. CNC milling machine specification

\begin{tabular}{|c|c|c|}
\hline No & Part name & Specification \\
\hline 1 & 3-axis machine center & Spinner \\
\hline 2 & Model & BFW45 \\
\hline 3 & Spindle driver & Servo motor \\
\hline 4 & Spindle range & 10 -6000 RPM \\
\hline 5 & Tool holder & ISO 40 \\
\hline 6 & Cutting fluid & NR \\
\hline 7 & Tool & HSS \\
\hline 8 & Work piece & Aluminum Alloy H20 and H20 \\
\hline 9 & Movement & $610 * 450$ \\
\hline 10 & Bed size & $800 * 500$ \\
\hline
\end{tabular}

Rotational speed 1000RPM, feed $20 \mathrm{~mm}$ and travel speed $20 \mathrm{~mm} / \mathrm{m}$ used for the process. In addition, Aluminum Alloy $\mathrm{H} 20$ and $\mathrm{H} 20$ applied in this investigation and the dimension of joint shown in figure 2. Besides Conventional (ordinary) and overlap joint FSW samples shown in figure 3 .

\section{Dimension of Joint}

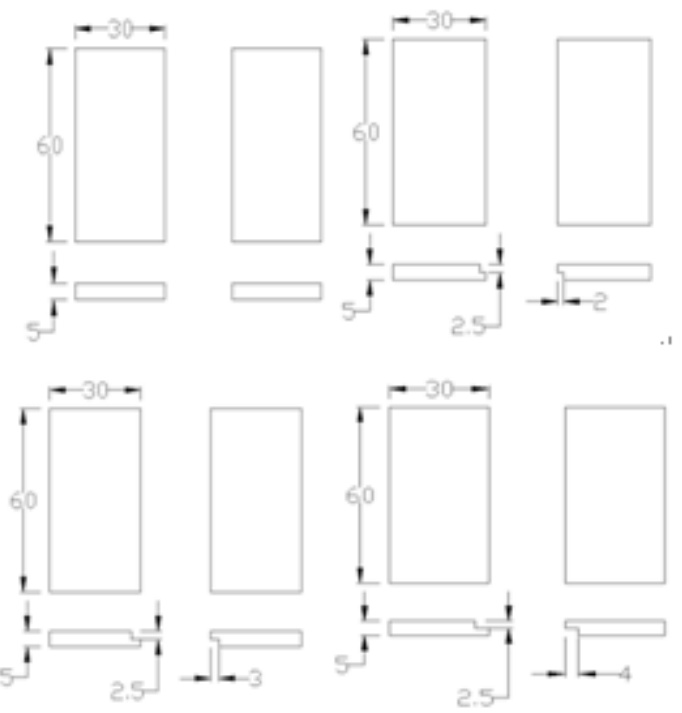

Figure 2. work piece demansions(conventional and overlap joints, overlap joints with different depth)

\section{CNC Program}

The process of welding by following program in our CNC milling machine performed. The same program but by reverse direction used for the back side of the weld joints the applied CNC program is as following:

00010(DIA 16.0EM 45 DEGEREE TIP CUTTER)

N01 (FRICTION STIR WELDING)

N02 (DATE 11-01-2010 TIME 20:15:08)

N03 G0G17G40G49G53G80G90

N04 G5.1Q1R10

N05 G91G28Z0

N06 M03S950

N07 G90G54X0.0Y0.0

N08 G43H6Z50

N09 G1Z2F800

N10 G1Z-3.8F16

N11 X170

N12 G0Z50.0M09

N13 M05

N14 G91G28Z0

N15 G5.1Q0

N16 M3 


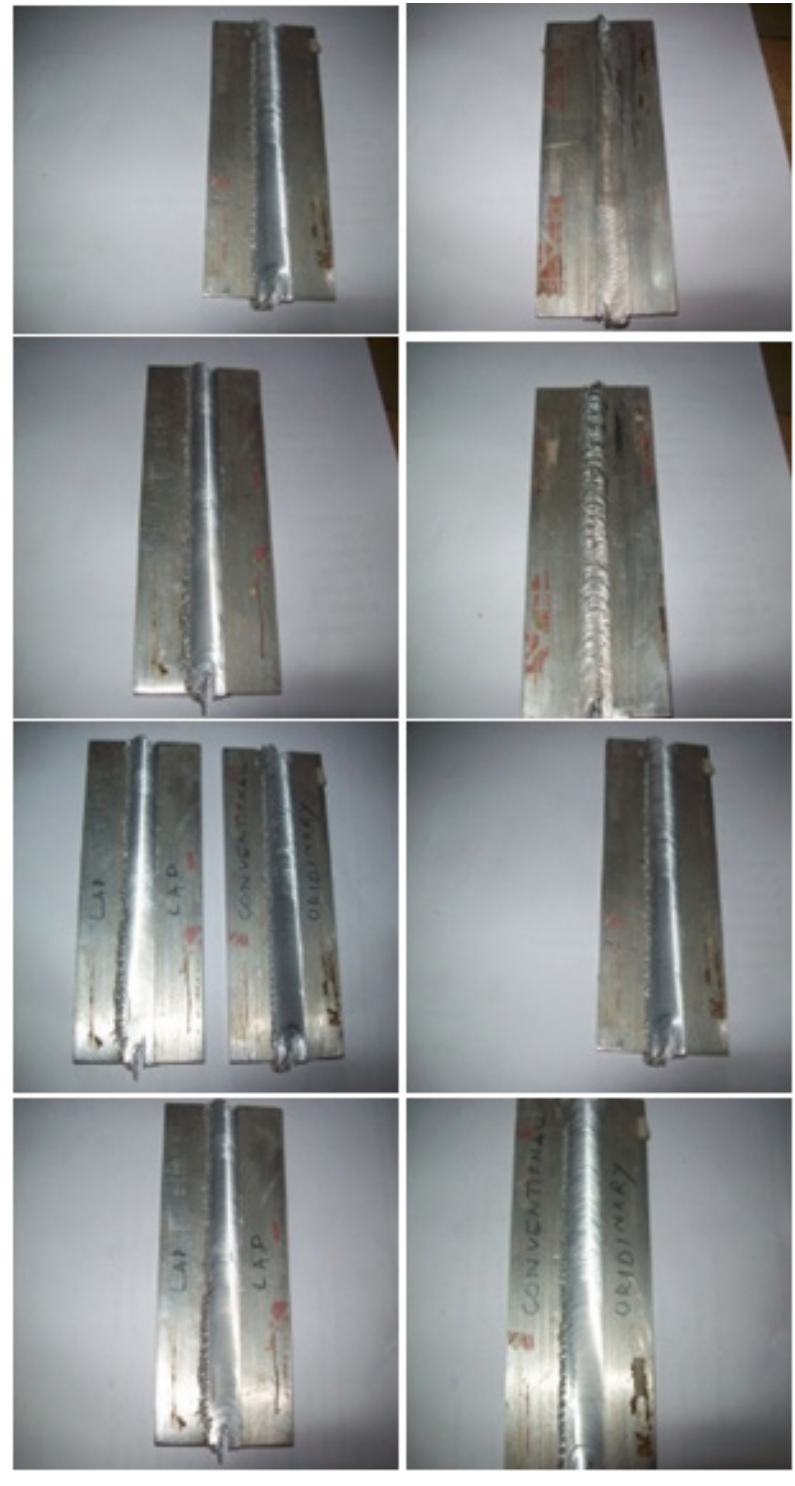

Figure 3. Conventional (ordinary) and overlap joint FSW samples

\section{Weld Testing Procedures}

Tensile test performed by universal testing machine. Testing performed in temperature between 10 to $35^{\circ} \mathrm{C}$ if $\mathrm{S}$ is Cross-sectional area and $\mathrm{F}$ is the maximum force and Tensile strength calculated by [5]:

$$
\text { Tensile strength }=\mathrm{R}=\mathrm{F} / \mathrm{S}
$$

Vickers Hardness Test based on the principal that the testing tool applies to the work piece welded joint. The geometry of changing in the work piece could identify vicker hardness numbers with assist of following formula. If $\mathrm{P}$ is applied load by Pyramid shape diamond $(\mathrm{kg}), \mathrm{L}$ is area of indentation $(\mathrm{mm})$ and $\alpha$ is angle between opposite faces of diamond = $136^{\circ}[6]$ :

$$
\mathrm{DPH}=2 \mathrm{P} \sin (\alpha / 2) / \mathrm{L}^{2}
$$

The process parameter optimization have a direct influence in welded joint quality It was found that rotating speed of pin, feed rate and the profile of the pin had significant effects on the strength of the welded-joints. When the real strain and tensile curves of the welded samples connected by increasing the rotating speed of the pin and feed rate were examined, high heat generation was observed [7].

The most important item in process parameter that has the approximately 50 percent influences on weld quality is pin length parameter or tool geometry and it has more influence on quality performance of weld [8]. The tool geometry used in this project shown in figure 4 .

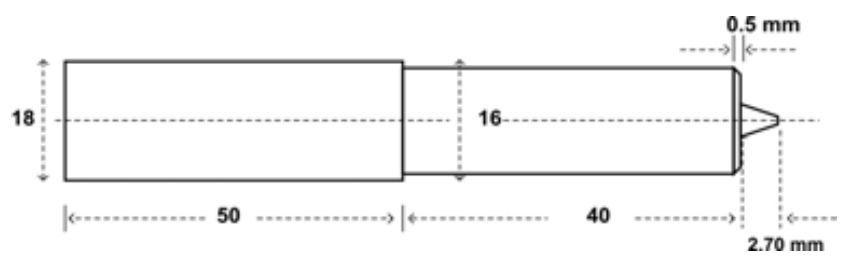

Figure 4. Tool Geometry

The tool type is triangular and the tool material is High speed steel (Wc-Co). Besides, general failure modes which can occur during tensile-shear test represented in figure 5 .

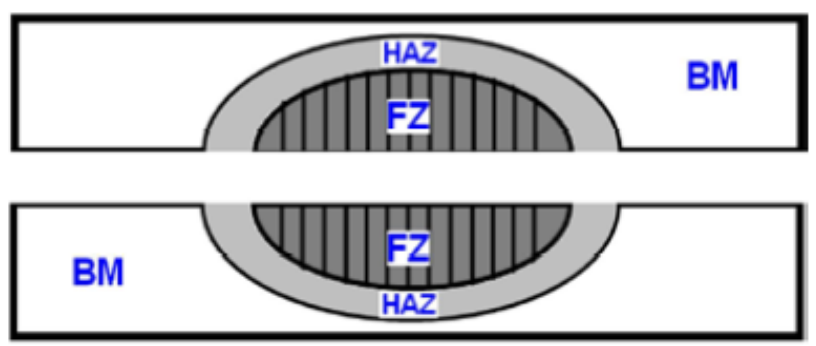

Figure 5. Schematic representation of general failure modes which can occur during tensile-shear test [9]

Fusion zone comes in FSW by assist of heat generated by friction between tool and work pieces. The solid-state nature of FSW leads to several advantages over fusion welding methods as problems associated with cooling from the liquid phase are avoided. Issues such as porosity, solute redistribution, solidification cracking and liquation cracking do not arise during FSW. In general, FSW has been found to produce a low concentration of defects and is very tolerant of variations in parameters and materials. Universal testing machine model DTU-9000HCA used in this investigation.

\section{Results}

In this investigation both side of joints welded first by conventional joint and after that by overlap joint with $2 \mathrm{~mm}, 3 \mathrm{~mm}, 4 \mathrm{~mm}$. in previous investigation we performed vicker hardness test for all conventional and overlap joint prepared by FSW with same material and tool and work procedure and respectively the result show in charts 1 to 4.Vickers hardness number varied by changing the Distance 
from the weld start position in center but there is not a meaningful relationship between them . besides,Tesile $\mathrm{s}$ trength of conventional and overlap joints diagram shown in chart 5 .

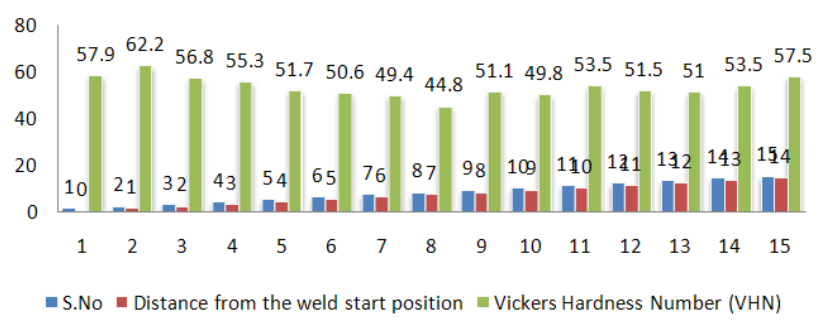

Chart 1. Distance from the weld start position Vs Vickers Hardness number (VHN)Conventional Joints

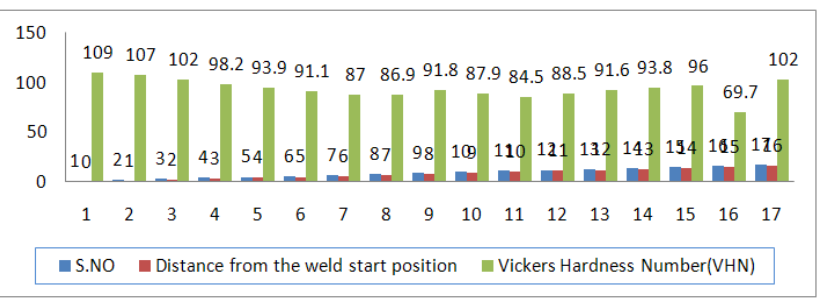

Chart 2. Distance from the weld start position Vs Vickers Hardness number (VHN)2 $\mathrm{mm}$ overlap distance weld joints

$$
\begin{aligned}
& \text { - S.No } \text { Distance from the weld start position } \quad \text { Vickers Hardness Number(VHN) }
\end{aligned}
$$

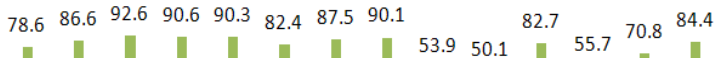

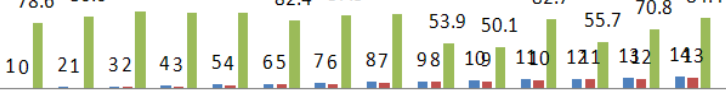

$$
\begin{aligned}
& \begin{array}{lllllllllllllll}
1 & 2 & 3 & 4 & 5 & 6 & 7 & 8 & 9 & 10 & 11 & 12 & 13 & 14 & 15
\end{array}
\end{aligned}
$$

Chart 3. Distance from the weld start position Vs Vickers Hardness number (VHN)3 mm overlap distance weld joints

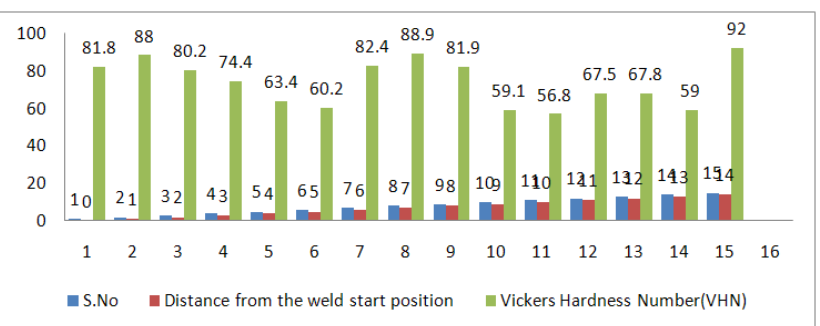

Chart 4. Distance from the weld start position Vs Vickers Hardness number (VHN)4 $\mathrm{mm}$ overlap distance weld joints

\section{Discussion}

By combining the test results in a unique chart we can achieve better understanding of the joints mechanical properties. Vicker hardness numbers for friction stir welded for different type of joints represented in table 2 and chart 6 . Besides, tensile strength in MPa for friction stir welded for different type of joints represented in table 3 and chart 7.

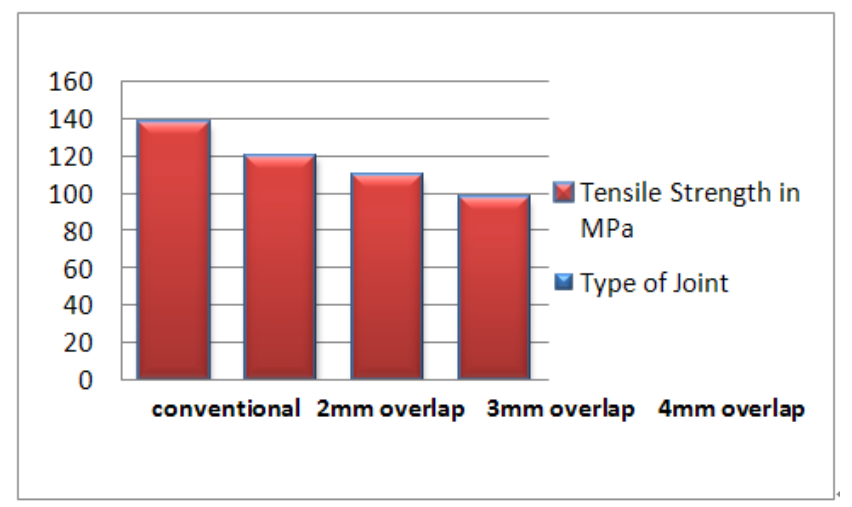

Chart 5. Tesile s trength of conventional and overlap joints diagram

At the end we can compare both tensile test and vicker hardness test numbers together this evaluation will help us in design process in different design situation and help us better understanding of FSW mechanical properties in conventional joint and in different overlap depth .better tensile characteristic will help when the welded joint under more horizontal load and bigger vicker hardness will help us when the welded joint under more vertical load. These seem to be important in design process we suppose that all numbers evaluated in optimal process parameter items like the main FSW process parameter rotational speed depth of process and travel speed. Effect of welding parameters on the microstructure of welded joint also is one of the items that directly have important influence on welded joint quality and mechanical properties [10]. Weld dilution is an important feature of weld bead geometry that determines the mechanical and chemical properties of a welded joint this may be another factor that is important in process parameter optimization. Mathematical models were developed in order to predict weld dilution as a function of process parameter that can be independently controlled and measure during any conventional or nonconventional welding processes [11]. In this study, Aluminum alloy joints were welded successfully by friction welding process for different lap joint gaps of 2 $\mathrm{mm}, 3 \mathrm{~mm}$ and $4 \mathrm{~mm}$ respectively. Some interesting developments of mechanical properties have been found to occur in the weldments. The tensile testing of the weld and vickers hardness number is influenced by the weld overlap of the plates. The effects of the weld overlap distance in the joints were investigated. The results obtained during reverse welding are tabulated and the VHN is plotted against the rotational speed of the spindle (FSW Tool). It is observed that the parent material shows variation in hardness even then the work pieces are cut from a same sheet. This hardness is compared with the weldment hardness along the seam of weld for different speed followed during performing the experiment. It is perceived that the weldment hardness in AA6351 varies from a minimum of 33.4 to a maximum of 73.2 percentage of the parent material. The maximum hardness of 73.2 percentage of the parent material has occurred in the minimum speed condition used as same as in the case of forward welding. This gives a strong indication 
that the hardness of friction stir weldments, both in forward and reverse welding processes seems to approach the hardness of the parent material at slow rotational speeds of the spindle with tool. The slow rotational speed indicates the speed which is just above the speed that requires creating the frictional heat for fusing the aluminum H20 - H20 work pieces together to form a metallurgical bond after welding.

Table 2. Friction stir welded joint aluminum alloy H20-H20 Vickers Hardness Number (VHN) different types of joints.

\begin{tabular}{|c|c|c|c|c|c|c|c|c|c|c|c|c|c|c|c|c|}
\hline \multirow{3}{*}{$\begin{array}{l}\text { Friction stir } \\
\text { welded joint } \\
\text { conventional }\end{array}$} & S.No & 1 & 2 & 3 & 4 & 5 & 6 & 7 & 8 & 9 & 10 & 11 & 12 & 13 & 14 & 15 \\
\hline & $\begin{array}{c}\text { Distance from } \\
\text { the weld start } \\
\text { position }\end{array}$ & 0 & 1 & 2 & 3 & 4 & 5 & 6 & 7 & 8 & 9 & 10 & 11 & 12 & 13 & 14 \\
\hline & $\begin{array}{l}\text { Vickers } \\
\text { Hardness } \\
\text { Number } \\
\text { (VHN) } \\
\end{array}$ & 57.9 & 62.2 & 56.8 & 55.3 & 51.7 & 50.6 & 49.4 & 44.8 & 51.1 & 49.8 & 53.5 & 51.5 & 51.0 & 53.5 & 57.5 \\
\hline \multirow{3}{*}{$\begin{array}{l}\text { Friction stir } \\
\text { welded joint } \\
2 \mathrm{~mm} \\
\text { overlap } \\
\text { distance } \\
\text { weld joints }\end{array}$} & S.No & 1 & 2 & 3 & 4 & 5 & 6 & 7 & 8 & 9 & 10 & 11 & 12 & 13 & 14 & 15 \\
\hline & $\begin{array}{c}\text { Distance from } \\
\text { the weld start } \\
\text { position }\end{array}$ & 0 & 1 & 2 & 3 & 4 & 5 & 6 & 7 & 8 & 9 & 10 & 11 & 12 & 13 & 14 \\
\hline & $\begin{array}{c}\text { Vickers } \\
\text { Hardness } \\
\text { Number } \\
\text { (VHN) } \\
\end{array}$ & 109 & 107 & 102 & 98.2 & 93.9 & 91.1 & 87 & 86.9 & 91.8 & 87.9 & 84.5 & 88.5 & 91.6 & 93.8 & 96 \\
\hline \multirow{3}{*}{$\begin{array}{l}\text { Friction stir } \\
\text { welded joint } \\
3 \mathrm{~mm} \\
\text { overlap } \\
\text { distance } \\
\text { weld joints }\end{array}$} & S.No & 1 & 2 & 3 & 4 & 5 & 6 & 7 & 8 & 9 & 10 & 11 & 12 & 13 & 14 & 15 \\
\hline & $\begin{array}{c}\text { Distance from } \\
\text { the weld start } \\
\text { position }\end{array}$ & 0 & 1 & 2 & 3 & 4 & 5 & 6 & 7 & 8 & 9 & 10 & 11 & 12 & 13 & 14 \\
\hline & $\begin{array}{l}\text { Vickers } \\
\text { Hardness } \\
\text { Number } \\
(\mathrm{VHN}) \\
\end{array}$ & 78.6 & 86.6 & 92.6 & 90.6 & 90.3 & 82.4 & 87.5 & 90.1 & 53.9 & 50.1 & 82.7 & 55.7 & 70.8 & 84.4 & 87.3 \\
\hline \multirow{3}{*}{$\begin{array}{l}\text { Friction stir } \\
\text { welded joint } \\
4 \mathrm{~mm} \\
\text { overlap } \\
\text { distance } \\
\text { weld joints }\end{array}$} & S.No & 1 & 2 & 3 & 4 & 5 & 6 & 7 & 8 & 9 & 10 & 11 & 12 & 13 & 14 & 15 \\
\hline & $\begin{array}{c}\text { Distance from } \\
\text { the weld start } \\
\text { position }\end{array}$ & 0 & 1 & 2 & 3 & 4 & 5 & 6 & 7 & 8 & 9 & 10 & 11 & 12 & 13 & 14 \\
\hline & $\begin{array}{l}\text { Vickers } \\
\text { Hardness } \\
\text { Number } \\
(\mathrm{VHN}) \\
\end{array}$ & 81.8 & 88 & 80.2 & 74.4 & 63.4 & 60.2 & 82.4 & 88.9 & 81.9 & 59.1 & 56.8 & 67.5 & 67.8 & 59 & 92 \\
\hline
\end{tabular}

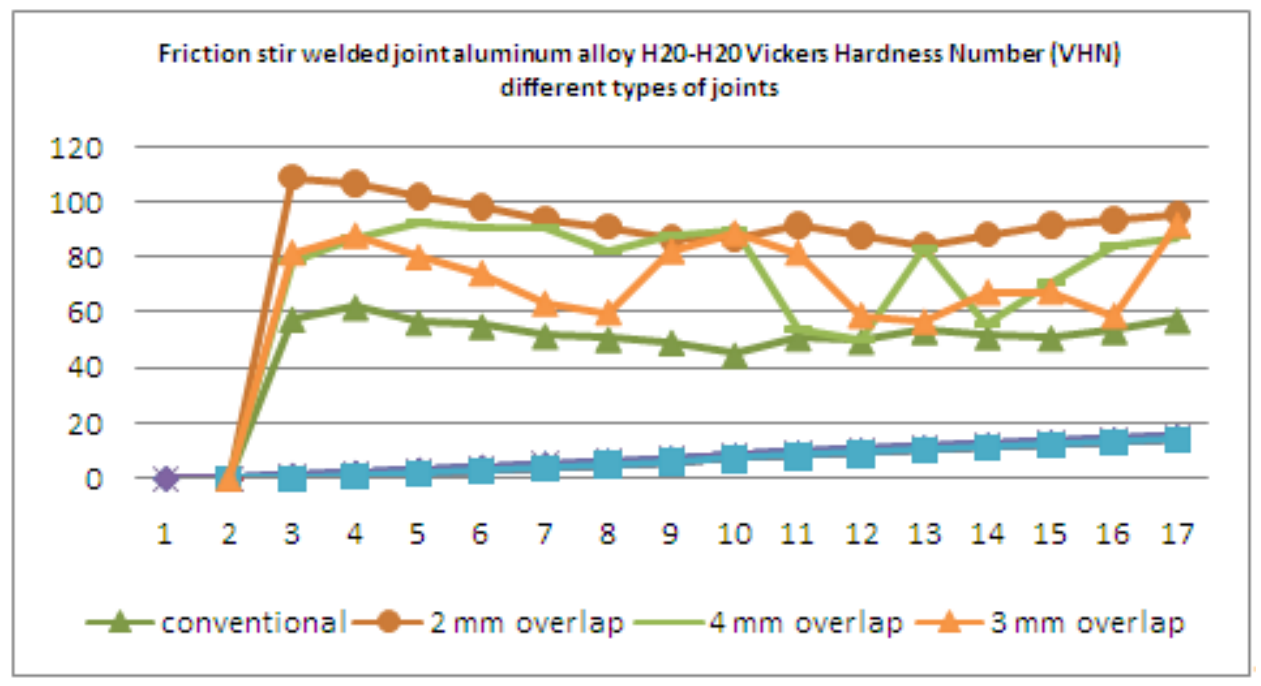

Chart 6. Vickers hardness numbers 
Table 3. Friction stir welded joint aluminum alloy H20-H20 Tensile Strength in MPa different types of joints

\begin{tabular}{|c|c|}
\hline Type of Joint & Tensile Strength in MPa \\
\hline Friction stir welded joint conventional & 138 \\
\hline Friction stir welded joint $2 \mathrm{~mm}$ overlap distance weld joints & 120 \\
\hline Friction stir welded joint $3 \mathrm{~mm}$ overlap distance weld joints & 109.5 \\
\hline Friction stir welded joint $4 \mathrm{~mm}$ overlap distance weld joints & 98 \\
\hline
\end{tabular}

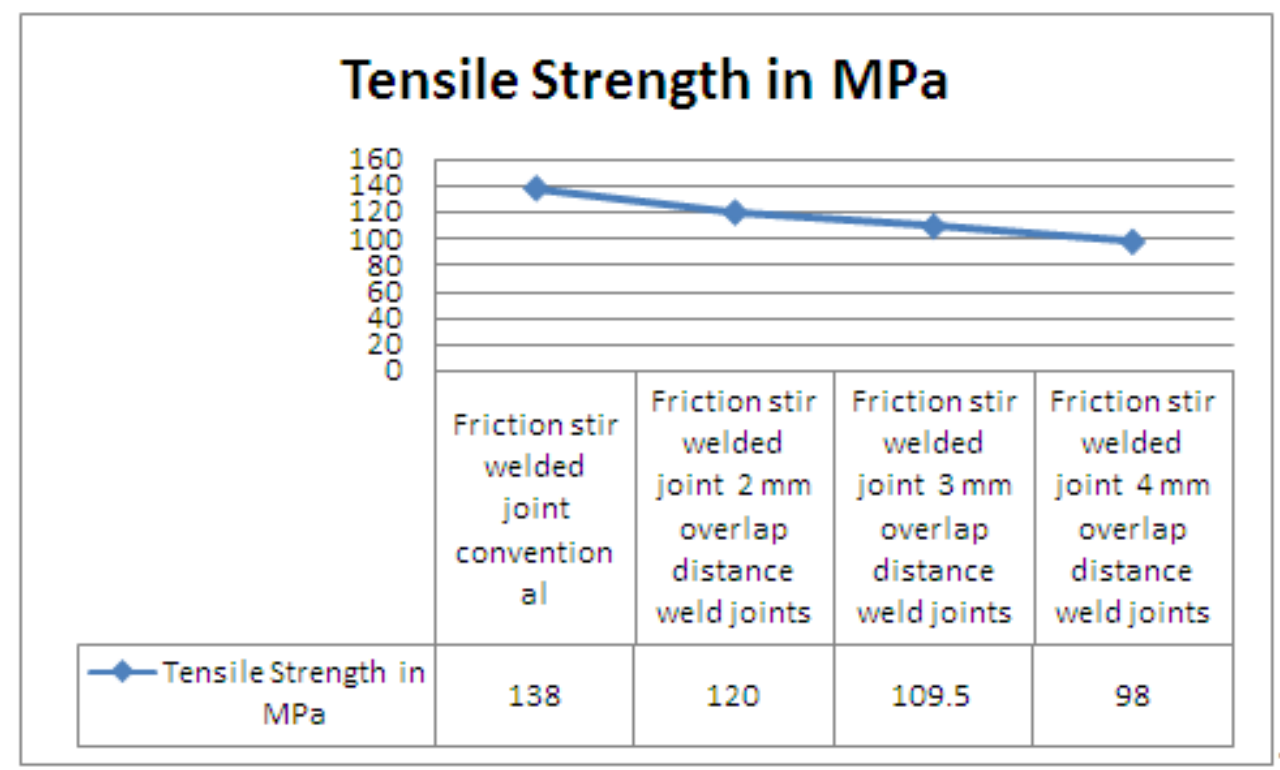

Chart 7. Tensile strength in MPa

\section{Conclusion}

FSW successfully done by CNC milling machine BMV 45 with acceptable quality. The mechanical properties of FSW vary by changing the position or distance from the center (weld position).FSW successfully done by similar work piece of aluminum alloy $\mathrm{H} 20-\mathrm{H} 20$ in both conventional and overlap joints. The vickers number varied by position of the joint (distance from weld center) and the hardness number is about 75 percent of aluminum alloy H20 (parent material).Conventional joint weld have the better tensile strength properties than overlap joint also Tensile Strength in MPa decreasing by lap distances MM increased in overlap joints. This results suggest that during the design process when the joint will under high vertical position load and hardness qualification required that is better to use overlap joints on the other hand when the joint is under horizontal load and tensile qualification required that is better to design conventional joint.

\section{Acknowledgements}

It is with great pleasure and deep sense of gratitude, that I acknowledge the successful completion of this project. My profound thanks and deep sense of gratitude to my respected internal guide Dr. M .MANZOOR HUSSAIN, Professor for his guidance and encouragement which were instrumental in the successful completion of my project, Also I would like to thank all the members and friends who helped me directly or indirectly to make this project a success. This project would have been impossible if not for perpetual moral support from my family members. I would like to thank them all.

\section{REFERENCES}

[1] R. S. Mishra and Z. Y. Ma: 'Friction stir welding and processing', Mater. Sci . Eng. A, 2005, 50, (1-66).

[2] H. Uzun, Friction stir welding of $\mathrm{SiC}$ particulate reinforced AA2124 Aluminum alloy matrix composite, Materials and Design 28 (2007)

[3] Resistance Spot Welding Characteristic of Ferrite-Martensite DP600 Dual Phase Advanced High Strength Steel-Part III: Mechanical Properties,2011, 1M. Pouranvari and 2E.Ranjbarnoodeh, World Applied Sciences Journal 15 (11): 1521-1526, 2011, @ IDOSI Publications, 2011.

[4] W.M.Thomas, E.D.Nicholas, J.C.Needham, M.G.Murch, P. Temple-Smith, C.J.Dawes, Friction stir butt welding 1995-46.

[5] T. Khaled: An outsider looks at friction stir welding, Technical report, Federal Aviation Administration, 2005-4.

[6] 'Evaluation Of Parameters Of Friction Stir Welding For Aluminum Aa6351 Alloy' by Ahmed Khalid Hussain and 
Syed Azam Pasha Quadri-International Journal of Engineering Science and Technology, Vol. 2(10), 2010, $5977-5984$.

[7] Effects of Rotating Speed and Feed Rate on Mechanical Behaviors in EN-AW6060 Aluminum Alloys Bonded by Using Friction Stir Welding,2013,hsanKüçükrendeci and 2Hasan Küçük,World Applied Sciences Journal 22 (4): 577-582, 2013, (C) IDOSI Publications, 2013.

[8] Optimizing the Process Parameters of FSW on AZ31B Mg Alloy by Taguchi-Grey Method,2013,Ram Kumar, M. Siva Pragash and Saji Varghese,Middle-East Journal of Scientific Research 15 (1): 161-167, 2013, (C) IDOSI Publications, 2013.

[9] Resistance Spot Welding Characteristic of
Ferrite-MartensiteDP600 Dual Phase Advanced High Strength Steel-Part II: Failure Mode,2011,1M. Pouranvari and 2E.Ranjbarnoodeh,World Applied Sciences Journal 15 (11): 1527-1531, 2011, C IDOSI Publications, 2011.

[10] Effect of Welding Parameters on Welding Microstructurein EN AW-6060Aluminum Alloy Combined with Friction Stir Welding Process,2013,IhsanKüçükrendeci,World Applied Sciences Journal 22 (3): 300-306, 2013, (C) IDOSI Publications, 2013.

[11] Prediction and Measurement of Weld Dilution in Robotic CO Arc Welding , 2013,S.Thiru, Chew Lai Huat, KamaruzamanJusoff, S. Hemavathi,World Applied Sciences Journal 21(Special Issue of Engineering and Technology): 23-30, 2013, (C) IDOSI Publications, 2013. 